assessment of therapeutic effect on post-CAR T-cell cases. The finding of enlarged lymph nodes by imaging study certainly raises concern of disease persistent or relapse.

Ethics Approval The study was approved by Fred Hutchinson Cancer Research Center's Ethics Board, approval numbers 1837, 9364

Consent Written informed consent was obtained from the patient for publication of this abstract and any accompanying images. A copy of the written consent is available for review by the Editor of the this journal.

http://dx.doi.org/10.1136/jitc-2020-SITC2020.0642

\section{AUTOPSY REVIEW OF CHIMERIC-ANTIGEN RECEPTOR T CELL THERAPY: A SINGLE INSTITUTION EXPERIENCE}

${ }^{1}$ KiBeom Kwon, ${ }^{2}$ David Woolston, ${ }^{2}$ Alexandre Hirayama, ${ }^{2}$ Damian Green, ${ }^{2}$ David Maloney, ${ }^{2}$ Cameron Turtle, ${ }^{2}$ Cecilia Yeung*. 'Seattle Cancer Care Alliance, Seattle, WA, USA; ${ }^{2}$ Fred Hutchinson Cancer Research Center, Seattle, WA, USA

Background Our institution has treated over 300 patients with chimeric antigen receptor (CAR) T-cell immunotherapy (CAR T-cell therapy) since 2013. Phase I and II trials were primarily based on heavily treated patients with B cell acute lymphoblastic leukemia (B-ALL), aggressive diffuse large B cell lymphoma (DLBCL), and multiple myeloma (MM) who had failed multiple lines of prior chemotherapy and/or hematopoietic stem cell transplantation (HSCT). In these relapsed and/or refractory patients, CAR-T therapy resulted in complete remission in $93 \%$ of B-ALL, $60 \%$ of DLBCL, and $\sim 80 \%$ of MM. Our Pathology Group at Fred Hutch have reviewed and diagnosed various patients with interesting relapse or complications as a result of CAR T-cell therapy. Here we present a retrospective review of autopsies from CAR T-cell therapy.

Methods A search for all autopsies conducted on patients from Seattle Cancer Care Alliance/University of Washington Medical Center was performed using the keywords 'CAR T' and 'Chimeric-antigen'. Our inclusion criteria were patients treated with CAR T-cell therapy. Pathology and clinical records were reviewed for cause of death, disease and treatment

Abstract 643 Table 1 Patient characteristics: age, sex, original diagnosis, CAR target, cause of death, and days post-CAR T-cell infusion at time of death

\begin{tabular}{|c|c|c|c|c|c|c|}
\hline $\begin{array}{c}\begin{array}{c}\text { Patient } \\
\text { code }\end{array} \\
\text { ovde }\end{array}$ & $\begin{array}{r}\text { Age at } \\
\text { death }\end{array}$ & Gender & $\begin{array}{l}\text { Original } \\
\text { diagnosis }\end{array}$ & CAR target & $\begin{array}{c}\text { Days post- } \\
\text { CAR infusion } \\
\text { upon death }\end{array}$ & Cause of Death \\
\hline 1 & 65 & м & DLBCL. & CD19 & P & $\begin{array}{l}\text { CRS/macrophage activation syndrome, endocarditis, } \\
\text { sepplic shock with hiver fialure, and extensive diffuse } \\
\text { large } \mathrm{B} \text { cell Iymphoma }\end{array}$ \\
\hline 2 & 48 & $\mathrm{~F}$ & ALL & CD19 & 3 & C. Difficile pseudonembranous colitis and CRS \\
\hline 3 & 55 & м & CLLSLL & CD19 & 90 & Aspergillus pneumonia \\
\hline 4 & 70 & м & DLBCL & CD19 & $\begin{array}{l}23 \text { (post-10 } \\
\text { iffusion) } \\
9 \text { (post-2.2 } \\
\text { infusion) }\end{array}$ & $\begin{array}{l}\text { Renal failure secondary to extensive involvement by } \\
\text { diffuse lange B cell lymphoma. }\end{array}$ \\
\hline 5 & 62 & M & DLBCL & CD19 & $\begin{array}{l}477 \text { (post- } 1^{*} \\
\text { infusion) } \\
\begin{array}{c}436 \text { (post- }-2^{4} \\
\text { infusion) }\end{array}\end{array}$ & $\begin{array}{l}\text { Polymicrobbal sepsss secondary to severer gratt versus- } \\
\text { host disease from allogeneic stem celt ransplant for } \\
\text { tratment of refractory DLBCL }\end{array}$ \\
\hline 6 & 46 & $\mathrm{~F}$ & ALL & CD19 & 10 & Clostridium septicum basceremia \\
\hline 7 & 60 & $\mathrm{~F}$ & мм & BCMA & 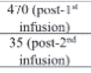 & $\begin{array}{l}\text { Disseminated fungal infection and coagulase negative } \\
\text { staph bacteremia, secondary to pancylopenia and CRS }\end{array}$ \\
\hline 8 & 61 & F & $\begin{array}{l}\text { Follicular } \\
\text { lymphoma }\end{array}$ & CD19 & 13 & Henorthagic infarction of the brainstem. \\
\hline 9 & 67 & M & мм & BCMA & 198 & 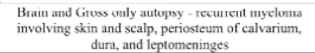 \\
\hline 10 & 62 & $\mathrm{~F}$ & CLL & CD19 & 4 & $\begin{array}{l}\text { Cardiac arrhythmia in the setting of mitral valve } \\
\text { annular calcinosis and cylokine release syndrome. }\end{array}$ \\
\hline 11 & 73 & м & $\begin{array}{c}\text { NHL- } \\
\text { BCLU } \\
\text { (Double } \\
\text { Hit) }\end{array}$ & CD19 & $\begin{array}{l}1439 \text { (post-1" } \\
\text { infusion) } \\
1390 \text { post } 2^{\text {at }} \\
\text { infusion }\end{array}$ & $\begin{array}{l}\text { Cardiac arrest frem stress cardionyopathy duc to } \\
\text { sepsis with right sided lung consolidations and } \\
\text { maxillary sinusitis }\end{array}$ \\
\hline 12 & 65 & м & DLBCL & CD19 & 47 & E. coli bacteremia, coagulopathy \\
\hline
\end{tabular}

timelines, microbiology data, cytokine levels, other pathology biopsies, and pertinent laboratory values. Histologic tissues were reviewed.

Results Twelve autopsies were performed since 2013. Patient characteristics and causes of death are summarized in table 1. The most common cause of death was due to infectious causes $(n=6)$. Two patients (Patients 10 and 11) had cardiovascular related deaths. Six patients (Patients 1, 2, 6, 7, 10, 12) suffered from CRS in their post-infusion course, four of whom (Patients 1, 2, 7, 10) had CRS directly attributed as the cause of death. CRS was further complicated by immune effector cell-associated neurotoxicity syndrome (ICANS) in 5 patients (Patients 1, 5, 6, 7, and 12). CRS with ICANS was the second most common cause of death in patients treated with CAR T-cells. Three patients (Patients 1, 4, 9) had progression of disease that attributed to cause of death.

Conclusions CAR T-cell therapy is a highly effective treatment even for patients who have relapsed and/or refractory disease. Post-therapy complications range in severity and may be fatal in rare instances as in the patients summarized in this study. Infection, CRS with ICANS are the most common causes of death in our single institution study.

Ethics Approval The study was approved by Fred Hutchinson Cancer Research Center's Institutional Review Board, approval number 1837

Consent Written informed consent was obtained from the patient for publication of this abstract and any accompanying images. A copy of the written consent is available for review by the Editor of this journal.

http://dx.doi.org/10.1136/jitc-2020-SITC2020.0643

\section{OCULAR ADVERSE EVENTS ASSOCIATED WITH PROGRAMMED DEATH-1 AND PROGRAMMED DEATH LIGAND-1 IMMUNOTHERAPY}

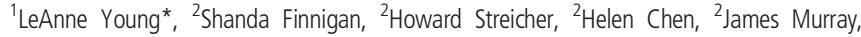
${ }^{1} \mathrm{H}$ Nida Sen, ${ }^{2}$ Elad Sharon. ${ }^{1}$ National Eye Institute, Cleveland, OH, USA; ${ }^{2}$ National Cancer Institute, Bethesda, MD, USA

Background The programmed death-1 (PD-1) and programmed death ligand-1 (PD-L1) inhibitors are increasingly studied and are known to have unique inflammatory side effects due to non-specific immune system activation. ${ }^{1}$ While rare, PD-1/PDL1 inhibitors can cause ocular toxicities, including inflammatory eye disease. $^{2}$ However, these ocular adverse events are less well-studied.

Methods This was a retrospective review of two adverse event (AE) monitoring databases maintained by the National Cancer Institute's Cancer Therapy Evaluation Program (CTEP), one of the largest public sponsors of clinical trials worldwide. One database (CTEP-AERS) is used for study sites to expeditiously report serious AEs for potential FDA review, while the other database (CDUS) is updated quarterly to reflect all the adverse events from the Phase 1 and Phase 2 trials in the CTEP network.

Results The two adverse event databases were queried for ocular adverse events up to May 19, 2020. A total of 331 adverse events from 259 patients were found. 73 patients (28\%) were exposed to nivolumab, 117 patients (45\%) were exposed to combination nivolumab and ipilimumab, 41 (16\%) were exposed to pembrolizumab, 26 (10\%) were exposed to atezolizumab, and $2(0.8 \%)$ were exposed to durvalumab. 59 adverse events from 47 patients were reported by the study 
site as serious AEs and had more detailed clinical information available. Ocular AEs occurred within several months of initiating the study treatment (all ocular AEs: median 6 weeks, IQR 0-18, ocular AEs reported as serious: median 12 weeks, IQR 6-20). CTCAE grade for ocular AEs was generally mild to moderate (all ocular AEs: grade 1, IQR 1-2, ocular AEs reported as serious: grade 2, IQR 2-3). Clinical workup and treatment varied for the ocular AEs reported as serious. 30/47 patients (64\%) receiving ophthalmologic evaluation.16/47 (34\%) of patients with serious ocular AEs had to delay or discontinue study drug treatment. However, 14/47 (30\%) had improvement in their ocular $\mathrm{AE}$ and $16 / 47$ patients (34\%) had resolution of their ocular AE. The most common ocular $\mathrm{AE}$ treatments in our dataset were steroids (intravenous, oral, and steroid eye drops).

Conclusions Ocular adverse events are rare complications of PD-1/PD-L1 inhibitor therapy, can be severe enough to cause PD-1/PD-L1 treatment discontinuation or delay, but patients may not always be referred to eye specialists. Future PD-1/ PD-L1 inhibitor studies would benefit from standardized plans for ophthalmologic evaluation of ocular toxicities.

\section{REFERENCES}

1. Postow MA, Sidlow R, Hellmann MD. Immune-related adverse events associated with immune checkpoint blockade. Longo DL, ed. N Engl J Med. 2018;378 (2):158-168

2. Dalvin $L A$, Shields $C L$, Orloff $M$, Sato $T$, Shields JA. Checkpoint inhibitor immune therapy. Retina 2018;38(6):1063-1078.

http://dx.doi.org/10.1136/jitc-2020-SITC2020.0644

\section{PRECLINICAL DEVELOPMENT OF A NOVEL COLON- TARGETED THERAPEUTIC FOR THE TREATMENT OF IMMUNE CHECKPOINT INHIBITOR (ICI)-COLITIS}

\footnotetext{
${ }^{1}$ Nazli Dizman*, ${ }^{2}$ Milton L Greenberg, ${ }^{2}$ Andrew C Newman, ${ }^{3}$ Jonathan Skupsky, ${ }^{4}$ JoAnn Hsu, ${ }^{4}$ Zeynep Zengin, ${ }^{4}$ Nicholas Salgia, ${ }^{4}$ Luis Meza, ${ }^{4}$ Neal Chawla, ${ }^{4}$ Sabrina Salgia, ${ }^{4} J a s n o o r$ Malhotra, ${ }^{4}$ Sumanta Pal. ${ }^{1}$ Yale New Haven Hospital, New Haven, CT, USA; ${ }^{2}$ Vivreon Gastrosciences, Inc., San Diego, CA, USA; ${ }^{3}$ VA Long Beach, Long Beach, CA, USA; ${ }^{4}$ City of Hope Comprehensive Cancer Center, Duarte, CA, USA
}

Background Immune Checkpoint Inhibitor (ICI) therapies have significantly improved overall survival in numerous cancers, but colitis has emerged as the most frequent dose-limiting toxicity associated with these therapies. Patients experiencing colitis side effects have to discontinue their cancer therapy to treat the colitis, which repositions life-threatening cancer. An ideal therapeutic would offer a colon-restricted approach to treating colitis side effects, while allowing patients to stay on their ICI therapy, an approach unavailable with currently approved therapies.

Methods To test this localized approach for the treatment of ICI-mediated colitis, we have developed a new chemical entity as a next-generation candidate therapeutic designed for oral administration. Permeability was tested in predictive epithelial monolayers and confirmed in rodent pharmacokinetic studies. We tested the drug in the preclinical adoptive transfer model for colitis. In this model, immunodeficient mice are hosts for adoptive transfer of naïve CD4+ T cells. In the absence of regulatory $\mathrm{T}$ cells, the transferred cells drive systemic inflammation and migrate to the colon, causing disease. Without treatment, these mice develop signs of colitis including weight loss, altered crypt architecture and infiltration of the lamina propria by week four. Furthermore, we developed a live biopsy culture system to test drug effects on ICI-colitis patient biopsies obtained via colonoscopy.

Results In-vitro studies demonstrate that the drug has minimal toxicity and that it potently suppresses $\mathrm{T}$ cell proliferation and cytokine secretion. Permeability studies show a limited ability to cross the colonic mucosa restricting anti-inflammatory effects to sites of ulceration and active colitis. When colitis mice were given drug by oral gavage after colitis had developed, treated mice showed a significant increase in weight over controls and improved histological scores. Importantly, markers of systemic inflammation remained unchained, and the cancer-killing ability of the primary ICI therapy was preserved. Results of the live biopsy culture studies will be presented.

Conclusions These preliminary studies demonstrate that the candidate therapeutic has potential to become a novel nextgeneration oral therapy for ICI-colitis because it effectively limits leukocyte function in-vitro and in-vivo with minimal systemic absorption and minimal expected side effects. Given the favorable drug profile and the rapid growth of ICI therapies, our colon-restricted colitis therapeutic has the potential to improve outcomes in a large number of cancer patients. We anticipate commencing first-in-human studies in Q4 of 2021.

Acknowledgements None

Ethics Approval The study was approved by City of Hope Cancer Center Institutional Review Board with the approval number of 19304.

http://dx.doi.org/10.1136/jitc-2020-SITC2020.0645

\section{EVALUATING A PRECLINICAL MODEL OF CONTACT HYPERSENSITIVITY FOR SKIN IMMUNE CHECKPOINT TOXICITY}

${ }^{1}$ Barbara Ma* ${ }^{2}$ Abhinav Jaiswal, ${ }^{2} \mathrm{~K}$ Sanjana Devi, ${ }^{2}$ Qingrong Huang, ${ }^{2}$ Joy Hsu, ${ }^{2} Y$ ong Liu, ${ }^{2}$ Niroshana Anandasabapathy. ${ }^{1}$ New York Presbyterian/Weill Cornell Medicine, New York, USA; ${ }^{2}$ Weill Cornell Medicine, New York, NY, USA

Background Immune checkpoint inhibitors (ICIs) are limited by the high incidence of immune-related adverse events (irAEs) occurring in up to $40 \%$ of solid tumor patients on anti-PD-1 monotherapy ${ }^{1} 2$ and 72\% in anti-CTLA-4/anti-PD1 combination. ${ }^{3} 4$ These toxicities can cause treatment cessation, hospitalization and even death. ${ }^{5-7}$ IrAEs are variable in severity, timing, onset, and remain poorly understood. Amongst the different toxicities, skin irAEs are most frequent, occur the earliest, and are correlated with a positive prognosis. ${ }^{4}$ However, there is a lack of preclinical models to study checkpoint toxicity. We evaluated a murine model of allergic contact dermatitis (contact hypersensitivity to 2,4-dinitrofluorobenzene) that is mediated by $\mathrm{CD} 8+\mathrm{T}$ cells to gain a mechanistic understanding of skin checkpoint toxicity.

Methods C57BL/6 mice ( $\mathrm{n}=5$ per group) were sensitized epicutaneously on shaved flank with hapten $0.5 \%$ DNFB on day -5 and elicited on their ears with DNFB on day 0 . Starting four weeks later, mice were treated with either anti-programmed cell death protein (PD-1) or isotype. At the time of the first recall challenge only, mice were given either anti-PD1 or isotype. Mice received subsequent rechallenges with DNFB to the ears and ear swelling was measured at various time points. Mice were depleted of circulating or skin CD8+ 